\title{
Sex Determination using Finger Length, Fingers Ratio, and Foot Dimensions in Fayoum Governorate
}

\author{
Ghada Moustafa Abd- Elazeem ${ }^{1}$ and Wafaa Yousef ${ }^{2}$
}

${ }^{1}$ Department of Forensic Medicine and Clinical Toxicology
${ }^{2}$ Department of Community Medicine

Faculty of Medicine, Fayoum University, Fayoum, Egypt.

\begin{abstract}
The determination of sex is statically the most important criterion in identification of identity as it excludes approximately half the population at risk. Sex assessment is one of the first essential steps in human identification, in both medico-legal cases and bio-archaeological contexts. Fragmentary human remains compromised by different types of inhumation or physical insults may frustrate the use of the traditional sex estimation methods, such as the analysis of the skull and pelvis. Currently, the application of discriminate functions to sex unidentified skeletal remains is steadily increasing. Human population exhibit some degree of sexual dimorphism which help sexual discrimination such that the male skeleton are on average larger than female thus allowing the size of skeleton to be used to estimate sex. The length of fingers and foot dimensions can determine the possibility of sexual dimorphism in addition to the interdigital ratios that do not depend on the body size, height, or age. Anthropometric measurements of the hand and foot dimensions (length and breadth) now become very important tool in sexual dimorphism detection in addition to the length of the small bone of the hand. This study aims to use of various parameters (length of the hand fingers and hand bone length, ratio between fingers) and foot dimensions ( length and breadth) in determination of the sex of individuals via the use of statistical analysis study was conducted on 200 Egyptian volunteer randomly selected adult 20-35 years old(100 male and 100 female), from Fayoum city. All subjects were healthy, had no fracture or disease .The mean age of the studied group of male volunteers is 21.40 years while that of female is 22.37 years old. The length of the fingers of males measured using a spreading caliber (the thumb is excluded) each finger given a number $2 \mathrm{~F}, 3 \mathrm{~F}, 4 \mathrm{~F}, 5 \mathrm{~F}$ for index , middle, ring and little finger respectively, same is done for the female.

The finger length is the distance between the tips of the finger till proximal flexion crease of that finger. The ratio between fingers is measured and named after with sex possibility $(2 f / 3 f, 2 f / 4 f, 2 f / 5 f, 3 f, 4 f$, $3 \mathrm{f} / 5 \mathrm{f}, 4 \mathrm{f} / 5 \mathrm{f}$ ). The results are analyzed statistically using SPSS program calculating the mean ,S.D and S.E. T test is used to compare different finger length ratio between fingers, and foot dimensions, and the $\mathrm{p}$ value is calculated. The results prove that the mean length of male fingers is more than that of female and the $2 \mathrm{f} / 3 \mathrm{f}, 2 \mathrm{f} / 4 \mathrm{f}, 2 \mathrm{f} / 5 \mathrm{f}$ of the male and female right hand is highly significant less than 0.001 also $3 \mathrm{f} / 4 \mathrm{f}$. While regarding to foot dimensions, the mean value were larger in left foot than the right. The foot length was the measurement with the greatest sex difference in both feet. In both feet, the length was the most sensitive variable $93 \%$ with $98 \%$ accuracy in left foot and $83 \%$ in right foot. In all age groups, the foot index in female was found to be more than 36, and less than 36 in male. Therefore, this value 36 can be used as deviation point for the determination of sex; hence, we can use these variants as sex determinant.
\end{abstract}

\section{Introduction}

$\mathrm{T}$ he determination of sex is statically the most important criterion in identification of identity as it excludes approximately half the population at risk (Saukko and Knight, 1996).

Sex assessment is one of the first essential steps in human identification, in both medico-legal cases and bio-archaeological contexts. Fragmentary human remains compromised by different types of inhumation or physical insults may frustrate the use of the traditional sex estimation methods, such as the analysis of the skull and pelvis. Currently, the application of discriminate functions to sex the unidentified skeletal remains is steadily increasing (Paola et al., 2011).

Human population exhibit some degree of sexual dimorphism which help sexual discrimination 
such that the male skeleton are on average larger than female thus allowing the size of skeleton to be used to estimate sex (Tatarek and Sciulli, 2005).

Forensic anthropology is that branch of physical anthropology which for forensic purposes deals with the identification of more or less skeletalized remains known to be or suspected to be human remains (Douglass and Ubelaker, 2006).

Great interest in sexual dimorphism has been aroused for many years. Traditionally the pelvic bone was the most common bone used in sexual dimorphism in combination with the cranium. Now great interests in long bone anthropometric measurement to declare sexual dimorphism are of potential interest in research (Iscan, 2005).

Determination of sex from incomplete skeletal and decomposing human remains is particularly important in personal identification. Measurements of hand bones length have been shown to be sexually dimorphic in many nationalities. Since the validity of discriminant function equation in sex determination is specific (Eshak et al., 2011).

Sex determination is an important and one of the foremost criteria in establishing the identity of an individual. Identification of dismembered/severed human remains that are frequently found in cases of mass disasters and criminal mutilation is a challenging task for the medico legal experts. In an attempt to discuss the sexual dimorphism anthropometry of the hand can assist forensic experts in the identification of amputated/dismembered remains (Kanchan and Krishan, 2011)

Sex determination from prepubertal human remains is a challenge for forensic experts and physical anthropologists worldwide as definitive sexual traits are not manifested until after the full development of secondary sexual characters that appear during puberty (Kanchan et al., 2010).

Skull and pelvis offer the best information on sexing although the femur, sternum and small hand bone can offer assistance (Richard, 2003)

The length of fingers can determine the possibility of sexual dimorphism in addition to the interdigital ratios that do not depend on the body size, height, or age (Lippa, 2003)

Anthropometric measurements of the hand and foot dimensions (length and width) now become very important tool in sexual dimorphism detection in addition to the length of the small bones of the hand (William et al., 2000; Tanui K et al., 2010).

The notice of manning in 1998 on the ratio between the second and fourth finger received great attention by researchers as a longer index finger compared with the ring finger deserve attention (Kanchan et al., 2008).

\section{Aim of the work}

This study aims to use various parameters (length of the hand fingers and hand bone length, ratio between fingers) and foot dimension (length and breadth) in determination of the sex of individuals via the use of statistical analysis.

\section{Subjects and methods}

Two hundred adult Egyptian volunteer individuals (100 male and 100 female) 20-35 years old were randomly selected from Fayoum city. All individuals were healthy, had no fractures or diseases. Consent was previously taken from each one separately after explaining the purpose of this study.

Finger length: The length of the fingers of male's hands (right and left) is measured using a spreading caliber. The thumb is excluded. Each finger was given a number $2 \mathrm{~F}, 3 \mathrm{~F}, 4 \mathrm{~F}$, and $5 \mathrm{~F}$ for index, middle, ring and little finger respectively. The same is done for females.

The finger length is the distance between the tips of the finger till proximal flexion crease of that finger.

The ratio between fingers is measured and named after with sex possibility $(2 \mathrm{f} / 3 \mathrm{f}, 2 \mathrm{f} / 4 \mathrm{f}, 2 \mathrm{f} / 5 \mathrm{f}$, 3f/4f, 3f/5f, and 4f/5f).

Foot length: each subject was made to stand on a calibrated foot board with his/her back against the wall in such a manner that the posterior most point of the hell will gently touch the wall. A vertical stop was placed against the anterior most point of the foot. The distance between the posterior most point of hell and anterior projecting point (the end of greater toe or second toe) was measured as foot length; this measurement excluded any nail extending over the end of the toe as described by Taylor et al., 1981.

Foot breadth: was measured as straight distance from the most medially placed point on the head of $1^{\text {st }}$ metatarsal to the most laterally placed point located on the head of $5^{\text {th }}$ metatarsal (as show in figure $3)$.

All the measurements were taken on both sides in each subject. The measurements were taken in centimeters.

The results are analyzed statistically using SPSS program calculating the mean, standard deviation (S.D) and student-T test is used to compare different finger length ratio between fingers, and foot dimension foot index was used in determination of sex and the $p$ value is calculated.

The receiver operating characteristic (ROC) curve is a method testing the efficiency of determination of sex from variables \pm detecting the rate of false positive and false negative measurements (overlap or close similarity) between some male and female measurements. The ROC curve used in the study and each variable was analyzed in relation to the cut off (sectional) value. It is a definite value which can demarcate between false positive and false negative measurement. Sensitivity (percentage in which the curve can detect positive cases), specificity (percentage in which the curve can detect false positive cases) Accuracy (percentage in which the curve can detect true positive and false positive cases (Flash and $\mathrm{Wu}$, 2003). 


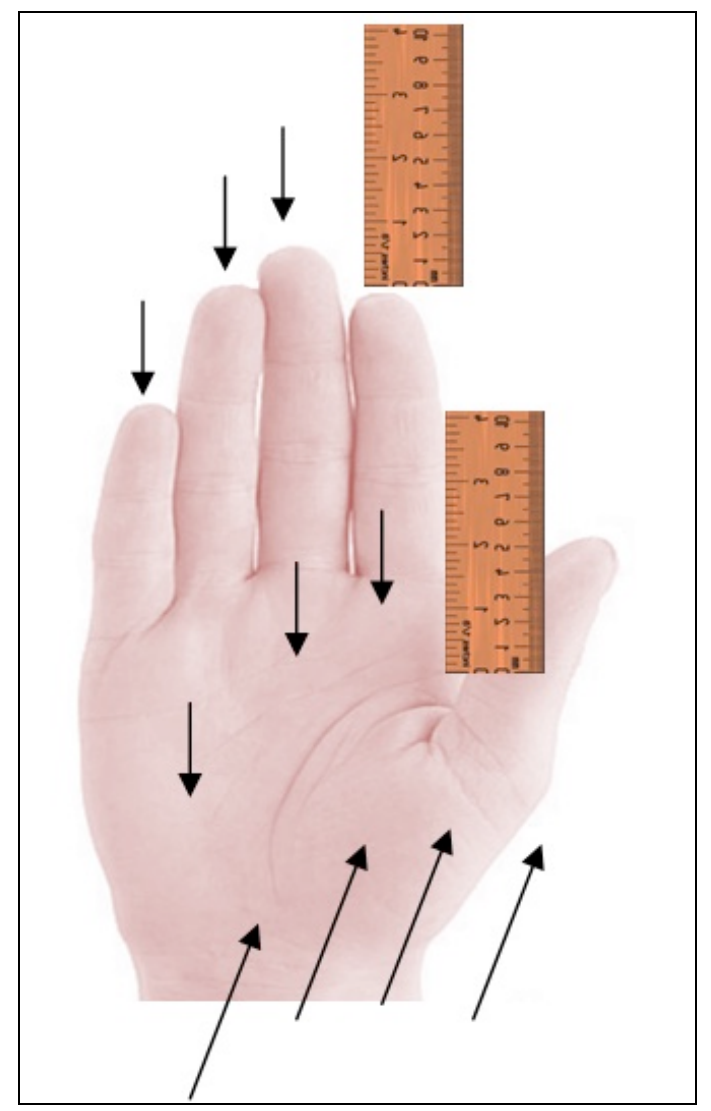

Figure 1: female hand anthropometry

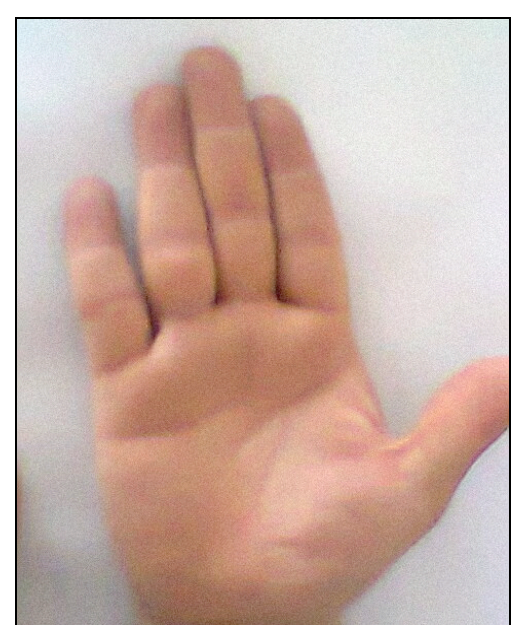

Figure 2: male hand anthropometry.

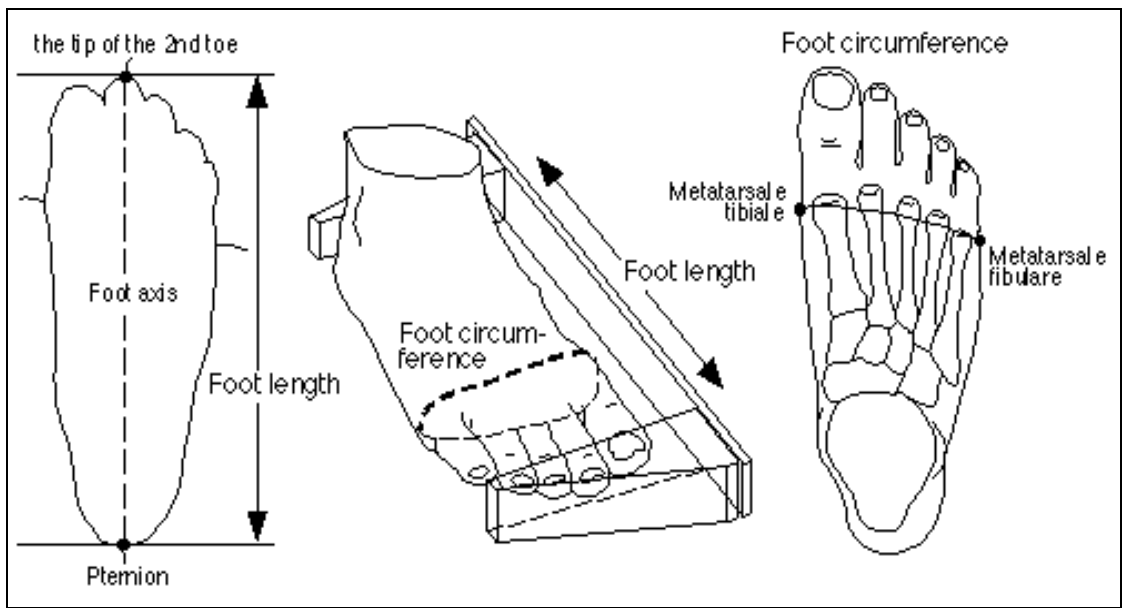

Figure 3: measurement of foot dimensions. 


\section{Results}

The study conducted on 200 adult volunteers (100 for each sex) residents at Fayoum city. The mean age of male persons is 21.4 years while that of female persons is 22.3 years.

Mean finger length of male and female Right and Left hand is shown (in table 1) from which we notice the mean length of male fingers is more than that of the female fingers for both hands. The lengths of the fingers of the left hand of male persons are averagely more than those of the fingers of the right hand with some exception of the $5^{\text {th }}$ fingers. The $4^{\text {th }}$ finger of the hand is longer than the second finger while in female it is equal or nearly equal in length. In female hands the $3^{\text {rd }}$ finger is equal in right and left hand while the $4^{\text {th }}$ and $5^{\text {th }}$ finger are longer in the left than in the right hand. On the opposite, the $2^{\text {nd }}$ finger is longer in the right than in the left hand.

The finger length of the male hand are in order from longer to shorter $3^{\text {rd }}, 4^{\text {th }}, 2^{\text {nd }}$, then $5^{\text {th }}$ finger. In female hand the order is $3^{\text {rd }}, 2^{\text {nd }}, 4^{\text {th }}$, and $5^{\text {th }}$ in right hand while it is as that of male in the left hand of female.

The S.D and student-T test is seen in (table 1) with highly significant $p$ value less than 0,001 .

We notice from (table 2 ) that the $p$ value of the $2 \mathrm{f} / 3 \mathrm{f}, 2 \mathrm{f} / 4 \mathrm{f}, 2 \mathrm{f} / 5 \mathrm{f}$ of the male and female right hand is highly significant less than 0,001 also $3 \mathrm{f} / 4 \mathrm{f}$ is highly significant less than .001 .while that of $3 \mathrm{f} / 5 \mathrm{f}$ of the ratio of male and female right hand is significant $p$ value is less than 0.001 . While the $p$ value of the ratio between 4f/5f (Right) and 2f/3f, 2f/4f, 2f/5f, 3f/5f, 4f/5f (Left) hand of male and female is significant less than 1 .

The $p$ value of the ratio between the $3 f / 4 f$ (Left) hand is highly significant for male and female less than 0.001

The mean of $(2 \mathrm{f} / 3 \mathrm{f} \quad, 2 \mathrm{f} / 4 \mathrm{f}$ $, 2 f / 5 f, 3 f / 4 f, 3 f / 5 f, 4 f / 5 f)$ ratio is higher in female than male in right hand, The mean of $(2 \mathrm{f} / 3 \mathrm{f}, 2 \mathrm{f} / 4 \mathrm{f}, 2 \mathrm{f} / 5 \mathrm{f}$,
$3 f / 5 f, 3 f / 5 f$, ) ratio is higher in female than male Right hand, the mean of $(3 \mathrm{f} / 4 \mathrm{f}, 4 \mathrm{f} / 5 \mathrm{f})$ ratio is higher in male than female in Left hand

Table 3 showed that By using the univariate logistic regression which study the odd ratio (OD) that each ratio of fingers $(3 f / 5 f, 2 f / 3 f, 3 f / 4 f, 2 f, 4 f, 2 f / 5 f)$ in right hand is higher in female than male in odd ratio as seen in table 4 from it we can use these ratio to detect sex. Table 4 showed that the only predictor (accurate) of sex is the $2 \mathrm{f} / 4 \mathrm{f}$ ratio.

ROC curve was employed to detect best cut off point that differentiate between sex with minimum false results (false positive and false negative). Table 5 showed that the sensitive variable that differentiate between sex was Right F4 80\% sensitivity and the most specific and accurate test less false positive was Left F3 specificity $83 \%$, accuracy $81 \%$. Finger ratios are less sensitive and specific variable in detecting sex.

The results of descriptive statistical analysis are reported in Table 6 showing the mean value, standard deviation of each variable. The left $(\mathrm{t})$ value for comparison between males and females and their significance (p) are given.

Table7 reveals that mean values of foot dimensions (length and breadth of male and female Right and Left foot) are significantly greater in males than females, so all $\mathrm{t}$ values are highly significant $\mathrm{p}<0.001$ the foot length with the greatest sex difference in both feet.

Employing ROC curve (Table 8) to study each variable independently revealed that the accuracy of all measurements ranged from $87 \%$ to $90 \%$ in right foot and $87.5 \%$ for left foot. The breadth of right foot was coming first. The result also showed that foot length were the most sensitive variable in both feet $93.8 \%$.

As regards the foot index (Tables 9 and 10), it was found that in females more than 36 , while it was less than that in males, therefore, this value 36 can be used as deviation point for the determination of sex.

Table 1: Student-t test statistical analysis of hand variables (finger length by $\mathrm{cm}$ ) in males and females.

\begin{tabular}{|l|c|c|c|}
\hline \multirow{2}{*}{ Variable } & Males (n=100) & Females (n=100) & \multirow{2}{*}{ P } \\
\cline { 2 - 3 } & Mean \pm SD & Mean \pm SD & \\
\hline \multicolumn{4}{|c|}{ Right hand } \\
\hline 2F & $7.02 \pm 1.16$ & $6.56 \pm 0.40$ & 0.00 \\
\hline $3 \mathrm{~F}$ & $7.99 \pm 0.58$ & $7.31 \pm 0.46$ & 0.00 \\
\hline $4 \mathrm{~F}$ & $7.31 \pm 0.60$ & $6.51 \pm 0.47$ & 0.00 \\
\hline $5 \mathrm{~F}$ & $6.73 \pm 0.66$ & $6.73 \pm 0.43$ & 0.00 \\
\hline \multicolumn{4}{|c|}{ Left hand } \\
\hline $2 \mathrm{~F}$ & $7.17 \pm 0.65$ & $6.38 \pm 0.42$ & 0.00 \\
\hline $3 \mathrm{~F}$ & $8.24 \pm 0.69$ & $7.11 \pm 0.45$ & 0.00 \\
\hline $4 \mathrm{~F}$ & $7.325 \pm 0.613$ & $7.366 \pm 0.76$ & 0.00 \\
\hline $5 \mathrm{~F}$ & $6.172 \pm 0.68$ & $5.543 \pm 0.40$ & 0.00 \\
\hline
\end{tabular}


Table 2: Student-t test statistical analysis of finger ratios in males and females.

\begin{tabular}{|l|c|c|c|}
\hline \multirow{2}{*}{ Variable } & Males (n=100) & Females (n=100) & \multirow{2}{*}{ P } \\
\cline { 2 - 3 } & Mean \pm SD & Mean \pm SD & \\
\hline \multicolumn{4}{|c|}{ Right hand } \\
\hline $2 \mathrm{~F} / 3 \mathrm{~F}$ & $.87 \pm .04$ & $.91 \pm .04$ & 0.00 \\
\hline $2 \mathrm{~F} / 4 \mathrm{~F}$ & $.91 \pm .04$ & $.98 \pm .04$ & 0.00 \\
\hline $2 \mathrm{~F} / 5 \mathrm{~F}$ & $1.17 \pm .14$ & $1.26 \pm .15$ & 0.00 \\
\hline $3 \mathrm{~F} / 4 \mathrm{~F}$ & $1.07 \pm .05$ & $1.12 \pm .06$ & 0.00 \\
\hline $3 \mathrm{~F} / 5 \mathrm{~F}$ & $1.33 \pm .10$ & $1.38 \pm .14$ & .001 \\
\hline $4 \mathrm{~F} / 5 \mathrm{~F}$ & $1.25 \pm .08$ & $1.27 \pm .11$ & .111 \\
\hline \multicolumn{4}{|c|}{ Left hand } \\
\hline $2 \mathrm{~F} / 3 \mathrm{~F}$ & $.88 \pm .04$ & $.88 \pm .043$ & .745 \\
\hline $2 \mathrm{~F} / 4 \mathrm{~F}$ & $.90 \pm .05$ & $2.96 \pm 14.43$ & .155 \\
\hline $2 \mathrm{~F} / 5 \mathrm{~F}$ & $1.13 \pm .13$ & $1.15 \pm .08$ & .308 \\
\hline $3 \mathrm{~F} / 4 \mathrm{~F}$ & $1.10 \pm .11$ & $1.03 \pm .06$ & 0.00 \\
\hline $3 \mathrm{~F} / 5 \mathrm{~F}$ & $1.27 \pm 1.27$ & $1.29 \pm .11$ & .273 \\
\hline $4 \mathrm{~F} / 5 \mathrm{~F}$ & $2.31 \pm 1.67$ & $1.21 \pm .08$ & .301 \\
\hline
\end{tabular}

Table 3: Prediction of sex by univariate logistic regression.

\begin{tabular}{|l|c|c|c|c|c|}
\hline & \multirow{2}{*}{ B } & \multirow{2}{*}{ P } & \multirow{2}{*}{ OR } & \multicolumn{2}{|c|}{$\mathbf{9 5 . 0 \%}$ C.I for OR } \\
\cline { 5 - 6 } & & & & Lower & Upper \\
\hline 3f/5f Right & 3.6 & .002 & 37.9 & 3.8 & 377.9 \\
\hline Constant & 4.9 & .002 & .007 & & \\
\hline 2f/3f Right & 22.8 & .000 & $8.0 \mathrm{E} 9$ & $3.3 \mathrm{E} 6$ & $1.9 \mathrm{E} 13$ \\
\hline Constant & 20.3 & .000 & .000 & & \\
\hline 3f/4f Right & 13.8 & .000 & $1.0 \mathrm{E} 6$ & $6.1 \mathrm{E} 3$ & $1.8 \mathrm{E} 8$ \\
\hline Constant & 15.2 & .000 & .000 & & \\
\hline 2f/4f Right & 36.6 & .000 & $8.3 \mathrm{E} 15$ & $4.0 \mathrm{E} 11$ & $1.6 \mathrm{E} 20$ \\
\hline Constant & 34.9 & .000 & .000 & & \\
\hline 2f/5f Right & 4.0 & .000 & 56.4 & 7.5 & 421.0 \\
\hline Constant & 4.9 & .000 & .007 & & \\
\hline
\end{tabular}

$B$ and $P$ are variant; OR: odd ratio; $E=10^{\text {number }}$

Table 4: Prediction of sex by forward logistic regression (multivariate analysis).

\begin{tabular}{|c|c|c|c|c|c|c|}
\hline & \multirow{2}{*}{ B } & \multirow{2}{*}{$\mathbf{P}$} & \multirow{2}{*}{ OR } & \multicolumn{2}{|c|}{ 95.0\% C.I for OR } \\
\hline & & & & & Lower & Upper \\
\hline \multirow[t]{2}{*}{ Step $1^{\mathrm{a}}$} & 2f/4f Right & 36.6 & .000 & $8.3 \mathrm{E} 15$ & \multirow{2}{*}{$4.0 \mathrm{E} 11$} & \multirow{2}{*}{$1.6 \mathrm{E} 20$} \\
\hline & Constant & 34.9 & .000 & .000 & & \\
\hline \multirow[t]{2}{*}{ Step $1^{\mathrm{a}}$} & $3 \mathrm{f} / 4 \mathrm{f}$ Left & 8.6 & .000 & .000 & \multirow{2}{*}{.000} & \multirow{2}{*}{.005} \\
\hline & Constant & 9.2 & .000 & $1.0 \mathrm{E} 4$ & & \\
\hline
\end{tabular}

$B$ and $P$ are variant; $O R$ : odd ratio; $E=10^{\text {number }}$

Table 5: Sensitivity, specificity, and accuracy of different finger measurement and finger ratio by ROC curve.

\begin{tabular}{|l|c|c|c|c|}
\hline Variable & Cut off point & sensitivity & specificity & accuracy \\
\hline Right F3 & 7.55 & $78 \%$ & $69 \%$ & $73.5 \%$ \\
\hline Right F4 & 6.75 & $80 \%$ & $68 \%$ & $74 \%$ \\
\hline Left F2 & 6.65 & $75 \%$ & $70 \%$ & $72.5 \%$ \\
\hline Left f3 & 7.55 & $79 \%$ & $83 \%$ & $81 \%$ \\
\hline Left f5 & 5.85 & $69 \%$ & $74 \%$ & $71.5 \%$ \\
\hline 3f/4f Left & 1.025 & $67 \%$ & $50 \%$ & $58.5 \%$ \\
\hline 4f/5f Left & 1.225 & $59 \%$ & $59 \%$ & $59 \%$ \\
\hline
\end{tabular}


Table 6: Mean value, Sd, Std Error, of both male and females feet.

\begin{tabular}{|c|l|c|c|c|c|c|}
\hline Variable & Gender & Maxim & Minimum & Mean & SD & Std-Error \\
\hline Right foot breadth & $\mathrm{M}$ & 11.70 & 9.00 & 10.25 & .78825 & .197 \\
\cline { 2 - 7 } & $\mathrm{F}$ & 10.30 & 8.0 & 8.818 & .5088 & .127 \\
\hline \multirow{2}{*}{ Left foot breadth } & $\mathrm{M}$ & 10.8 & 9.2 & 10.18 & .611 & .152 \\
\cline { 2 - 7 } & $\mathrm{F}$ & 10.0 & 8.00 & 8.825 & .5579 & .1394 \\
\hline \multirow{2}{*}{ Right foot length } & $\mathrm{M}$ & 27.40 & 24.00 & 25.593 & & \\
\cline { 2 - 7 } & $\mathrm{F}$ & 25.50 & 22.30 & 23.625 & 1.037 & .259 \\
\hline Left foot length & $\mathrm{M}$ & 28.30 & 24.50 & 25.7188 & 1.199 & .299 \\
\cline { 2 - 7 } & $\mathrm{F}$ & 26.30 & 22.30 & 23.88 & 1.110 & .277 \\
\hline
\end{tabular}

Table 7: Mean value, student-t test, and $p$ value for both feet.

\begin{tabular}{|l|l|l|l|l|}
\hline \multirow{2}{*}{\multicolumn{1}{|c|}{ Variable }} & \multicolumn{1}{|c|}{ M } & \multicolumn{1}{|c|}{ F } & \multirow{2}{*}{ T } & P \\
\cline { 2 - 3 } & St \pm mean & St \pm mean & & \\
\hline Right foot length & \pm 25.59 & 8.818 & 5.4 & 0.00 \\
\hline Right foot breadth & $10.25 \pm 0.79$ & $8.82 \pm 0.51$ & 6.1 & 0.00 \\
\hline Left foot length & $25.72 \pm 1.19$ & $23.89 \pm 1.11$ & 4.48 & 0.00 \\
\hline Left foot breadth & $10.18 \pm 0.61$ & $8.82 \pm 0.558$ & 6.58 & 0.00 \\
\hline
\end{tabular}

Table 8: The cut off value, sensitivity, specificity and accuracy of Right and Left foot measurements.

\begin{tabular}{|l|c|c|c|c|}
\hline \multicolumn{1}{|c|}{ Variable } & Cut off point & sensitivity & specificity & accuracy \\
\hline Right foot length & 24.25 & $93 \%$ & $81.2 \%$ & $87.5 \%$ \\
\hline Right foot breadth & 9.1 & $93.8 \%$ & $87.5 \%$ & $90.6 \%$ \\
\hline Left foot length & 24.55 & $93.8 \%$ & $81.2 \%$ & $87.5 \%$ \\
\hline Left foot breadth & 9,45 & $87.5 \%$ & $87.5 \%$ & $87.5 \%$ \\
\hline
\end{tabular}

Table 9: Age wise distribution in foot index in male.

\begin{tabular}{|l|l|l|l|}
\hline Age (year) & Foot length & Foot Breadth & Foot index \\
\hline $21-24$ & & & \\
Right & 26.32 & 9.382 & 35.64 \\
Left & 26.53 & 9.481 & 35.73 \\
\hline $25-29$ & & & \\
Right & 26.73 & 9.62 & 35.98 \\
Left & 26.78 & 9.64 & 35.99 \\
\hline $30-34$ & & & \\
Right & 26.73 & 9.62 & 35.98 \\
Left & 26.78 & 9.64 & 35.99 \\
\hline $35-40$ & & & \\
Right & 26.89 & 9.68 & 35.9 \\
Left & 26.95 & 9.69 & 35.955 \\
\hline
\end{tabular}

Table 10: Age wise distribution in foot index in female.

\begin{tabular}{|l|l|l|l|}
\hline Age (year) & Foot length & Foot Breadth & Foot index \\
\hline 22-24 & & & \\
Right & 23.00 & 8.50 & 36.48 \\
Left & 23.65 & 8.65 & 36.57 \\
\hline $25-29$ & & & \\
Right & 23.7 & 8.7 & 36.7 \\
Left & 23.89 & 8.8 & 36.83 \\
\hline 30-34 & & & \\
Right & 25.2 & 9.1 & 36.11 \\
Left & 25.23 & 9.12 & 36.14 \\
\hline $35-37$ & & & \\
Right & 24.9 & 9.2 & 36.94 \\
Left & 25.52 & 9.32 & 36.80 \\
\hline
\end{tabular}

\section{Discussion}

The determination of sex is statically the most important criterion in identification of identity as it excludes approximately half the population at risk (Saukko and Knight, 1996).
Forensic anthropology is that branch for forensic purposes that deal with the identification of more or less skeletonized remains known to be or suspected to be human remains (Douglass and 
Ubelaker, 2006). Skull and pelvis offer the best information on sexing although the femur, sternum and small hand bone can offer assistance (Richard, 2003).

The extent and the length of fingers can determine the possibility of sexual dimorphism in addition to the interdigital ratios that do not depend on the body size, height, or age (Lippa, 2003).

Anthropometric measurements of the hand dimensions (length and width) in addition to the length of the small bone of the hand) now become very important tool in sexual dimorphism detection (William et al., 2000).

This study aims to use of various parameters (length of the hand fingers and hand bones, ratio between different measurements of fingers) in determination of the sex of individuals via the use of statistical analysis.

The order of finger length of the male hand are ordered from longer to shorter as $3^{\text {rd }}, 4^{\text {th }}, 2^{\text {nd }}, 5^{\text {th }}$ respectively, while that of female hand it is ordered $3^{\text {rd }}, 2^{\text {nd }}, 4^{\text {th }}$ and $5^{\text {th }}$ in right hand while in left hand of female it is as that of male the same results were found in the study conducted by McFadden and Shubel, 2002 in the USA (Texas) in the early $20^{\text {th }}$ century, also in the study conducted by Ghandour et al., 2009 in ARE (Assiut).

Mean finger length of the male and female Right and Left hand is shown (in Table 1) from which we notice the mean length of the fingers of male persons is more than that of the female fingers for both hands. The length of the fingers of the left hand of male persons nearly more than that of the fingers of the right hand with exception of the $5^{\text {th }}$ fingers which sometimes showed the reverse, these results are like those found by Aboul-Hagag et al., in their study on the hand length measurements at 2011. It also agree with the study done by Agnihotri et al., (2006), Where they found that the hand length is more longer in male than female hands and the right hand are longer than the left.

The $p$ value of the $2 f / 3 f, 2 f / 4 f, 2 f / 5 f, 3 f / 4 f$ of the male and female right hand is highly significant also, $3 \mathrm{f} / 4 \mathrm{f}$ (Left) and that of $3 \mathrm{f} / 5 \mathrm{f}$ of the ratio of male and female right hand is significant.

The $p$ value of the ratio between $4 \mathrm{f} / 5 \mathrm{f}$ (Right) and $2 \mathrm{f} / 3 \mathrm{f}, 2 \mathrm{f} / 4 \mathrm{f}, 2 \mathrm{f} / 5 \mathrm{f}, 3 \mathrm{f} / 5 \mathrm{f}, 4 \mathrm{f} / 5 \mathrm{f}$ (Left)hand of male and female is significant, where the $2 \mathrm{f} / 4 \mathrm{f}$ ratios the most accurate predictor of sex as that shown by McFadden and Shubel (2002), but other ratios can be used to predict sex in combination

As regards the result of foot dimensions, the present study was carried out to detect the possibility of sex prediction by using different measurements of foot belonging to same sample.

The result revealed that the mean values of foot dimensions are significantly greater in male when compared with females in both feet these result were in accordance with those of Anith O., et al., 2005. Who reported significant male and female difference in all foot dimensions in both feet.

The difference in foot dimensions between male and females could be explained as part of genetic expression that males being larger than females, in addition differences in body dimension among population and ethnic origins may be due to differences in nutrition, traditional habits and degree of physical activity (Tyagi et al., 2004)

When sex differences are noted, they are generally larger for left foot than right in humans (Kanchan et al., 2010) this observation agree with the present results in both sexes, also agree with Anitha et al., 2005, but contradict with Hilmi et al., 2004 in their study where the right foot length values were consistently higher than left. The reason for such side differences is uncertain but may be unequal distribution for motor skills or type of movement or may be some kind of work.

Regards foot index found that 36 can be used with fair accuracy for determination of sex and this is contraindicated with the study of A. Agnihotri et al., 2007 , in their study consider 37 was foot index

\section{Conclusion}

The study of the fingers length and ratio especially the $2 \mathrm{f} / 4 \mathrm{f}$ ratio and foot dimensions especially foot index could help sex determination among Egyptian populations.

\section{Recommendation}

- Application of other hand diameters could improve the accuracy of detection.

- X ray could be done and help the estimation of variants and determination of sex and certain this study.

\section{Reference}

Aboul-Hagag KE, Mohamed SA, Hilal MA, et al. (2011): Determination of sex from hand dimensions and index/ring finger length ratio in Upper Egyptians. The Egyptian Journal of Forensic Sciences 1(2):80-86.

Agnihotri AK, Purwar B, Jeebun N, et al., (2006): Determination of Sex by Hand Dimensions. The Internet Journal of Forensic Science. Volume 1 Number 2. DOI: 10.5580/1785.

Agnihotri AK, Shukla S, Purwar B. (2007): Determination of sex from foot measurements. Internal J. of Forensic Science.2, 3 .

Anitha O, Avinash M, and Tom O (2005): A study of the correlation between hand length and Foot length in human. J. Anat. Soc; India 54(2), 19.

Douglass H and Ubelaker S (2006): Anthropology and Medicine, Introduction to forensic Anthropology. 3;12.

Eshak G, Ahmed H, and Abdelgwad E (2011): Gender Determination from Hand Bone Length and Volume Using Multidirector Computed Tomography. J of Forensic Legal Medicine; 18(6):246-252. 
Flash P and Wu S (2003): Repairing concavities in ROC curve in: Proc.2003 UK workshop on computational intelligence. PP: 38-44.

Ghandour NM , George SM, Mohammed ZT, et al., (2009): Determination of Sex from Ratios of different Fingers Lengths in Upper Egypt Population Sample. Egypt J .Forensic Sci. Appl Toxicl, 9(1).

Hilmi O, Yasemin B, and Canan D (2005): Stature and sex estimate using foot and shoe dimensions. Forensic Science International, 147(2), 181184.

Iscan M (2005): Forensic Anthropology of Sex and Body Size. Forensic science international; 147:107-112.

Kanchan T and Krishan K (2011): Anthropometry of Hand in Sex Determination of Dismembered Remains. $\mathrm{J}$ of Forensic Legal Medicine: 18(1):14-7.

Kanchan T, Krishan K, Sharma A, et al., (2010): A study of correlation of hand and foot dimensions for personal identification in mass disasters. Forensic Science International, 199(1): 112.

Kanchan T, Kumar GP, and Menezes RG (2008): Index and ring finger ratio--a new sex determinant in south Indian population. Forensic Sci Int. 2008 Oct 25; 181(1-3):53.e14

Kanchan T, Kumar GP, Rosteg P, et al., (2010): Sexual Dimorphism of Index to Ring Finger in South
Indian Adolescent. J Forensic Leg Med. 17(5):243-6.

Lippa A (2003): Is 2D:4D finger length ratio related to sexual orientation? Yes for men, no for women. J Ppers Soc Psychol. 85:179:188.

McFadden D and Shubel E (2002): Relative lengths of fingers and toes in human males and females. Horm Behav. 42(4):492-500.

Paola M, Stefano D, Inmaculad L, et al., (2011): Sex Assessment from the Carpal Bone. Forensic Science International Journal. 206; 216.

Richard S (2003): The Identification of the Living and Dead. In: Simpson's Forensic Medicine, $12^{\text {th }}$ edition. pp 54.

Saukko P and Knight B (1996): Knight's Forensic pathology, infanticide, still birth and fatal child abuse. Arnold publisher, $3^{\text {rd }}$ edition, pp"461.

Tatarek NE and Sciulli PW (2005): Forensic Medicine of the Lower Extremity. Forensic Science and Medicine. Anthropological Analysis of the Lower Extremity, 69-98.

Taylor MC, Maclarnon AM, and Lanigan PM (1981): Foot length asymmetry, sex and handedness. Science; 212, 1416-1417.

Tyagi AK, Mukta R, Kohli A. (2004): Sexing of foot index. J. of Forensic medicine and Toxicology, 21(1), 10-11.

William T, Pepitone M, Christensen S, et al., (2000): Finger Length Ratios and Sexual Orientation. Nature; 404:455-456.

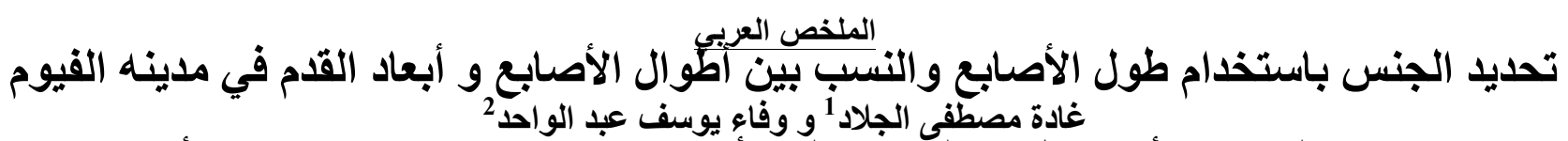

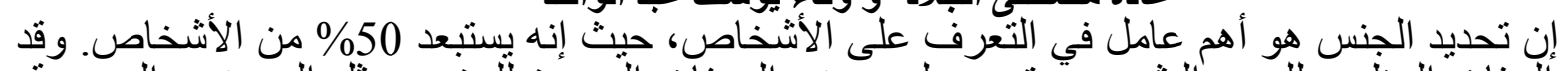

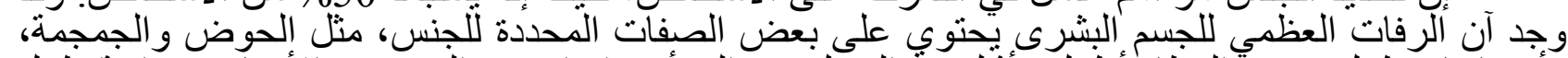

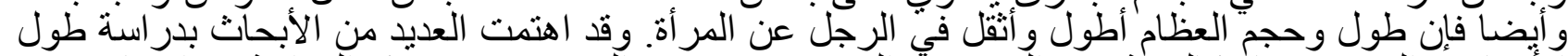

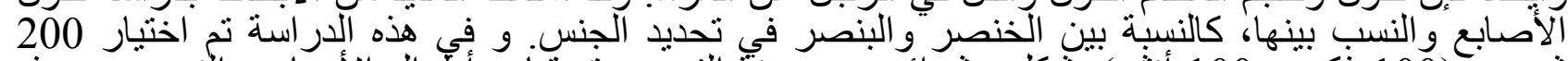

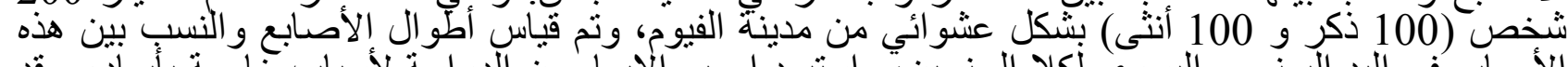

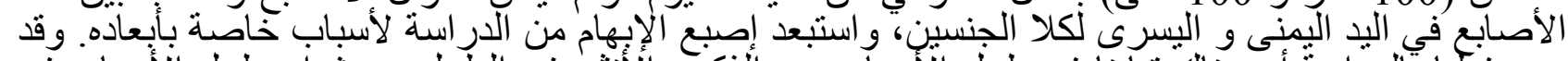

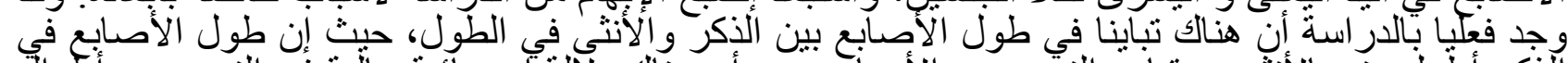

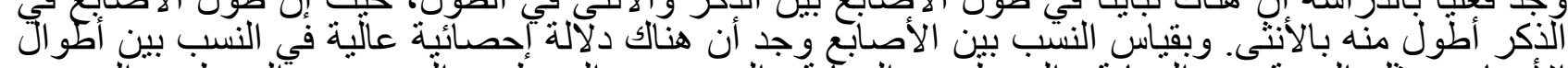

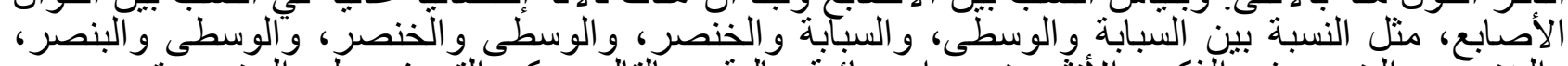
و الخنصر و البنصر في الذكر والأنتى بنسب إحصائية عالية، وبالنالي يمكن التعرف على الجنس وتحديده عن

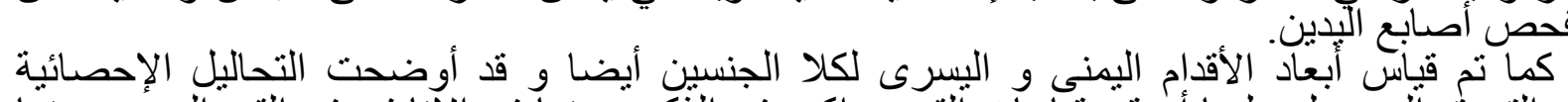

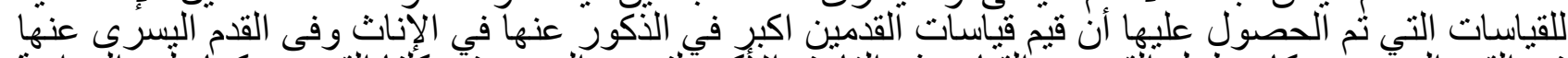

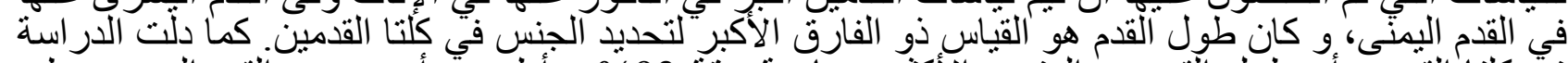

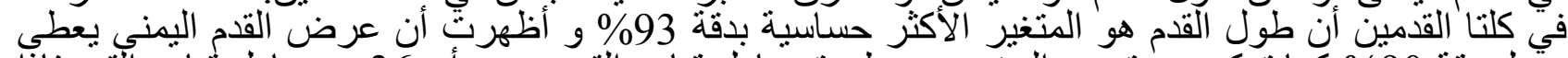

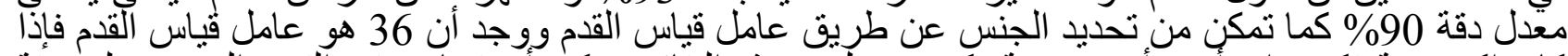

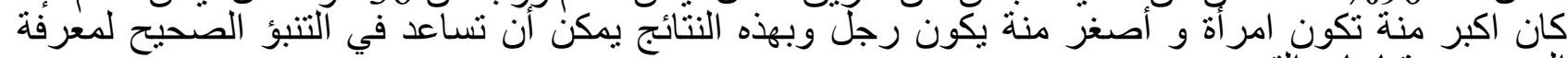

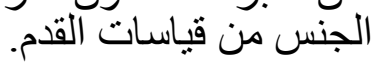

1 قسم الطب الثرعي والسموم الإكلينيكية كلية الطب جامعة الفيوم 